\title{
GEOGRAFIA DAS VESTIMENTAS: DOS CLÁSSICOS ÀS TENDÊNCIAS
}

\author{
GARMENT GEOGRAPH: FROM CLASSICS TO TRENDS \\ GÉOGRAPHIE DES VÊTEMENTS: DEPUIS LES CLASSICS AUX TENDANCES \\ Carlos Eduardo Santos Maia' - Universidade Federal de Juiz de Fora - Juiz de Fora - Minas Gerais - Brasil \\ carlmaia@uol.com.br
}

\begin{abstract}
Resumo
Inicialmente, as vestimentas são recortadas neste texto como objetos de investigação geográfica que permearam os trabalhos clássicos, geralmente sob a ótica do conceito de gênero de vida ou da relação homem-meio, e os estudos contemporâneos sobre indústrias de roupas. Neste artigo, porém, coloca-se propriamente a vestimenta como tema e perspectiva para abordarmos a constituição de espacialidades em casa e na rua. Melhor dizendo, indica-se a linguagem das vestimentas como instrumentos que nos possibilitam ler determinadas espacialidades e ainda entendê-las como definidoras de espaços-tempos.
\end{abstract}

Palavras-chave: vestimentas, casa, rua, espacialidade.

\section{Abstract}

Initially, garments serve in this paper as objects of geographical investigation which pervade classical works, generally under the concept perspective of the way of life or the man-environment relation, as well as contemporary studies about the clothing industries. In this article, however, garments are also used as a theme and as a perspective to address the constitution of spatialities at home and on the street. In other words, the language of garments is shown as tools that enable us to understand certain spatialities. In addition, it is demonstrated that the garments themselves represent a concept that defines space and time.

Key words: garments, home, street, spatiality.

\section{Résumé}

Initialement, les vêtements sont coupés dans ce texte comme objets de recherche géographique qui imprégnait les œuvres classiques, généralement du point de vue du concept de genre de vie ou de la relation hommeenvironnement, et les études contemporaines sur les industries de l'habillement. Toutefois, cet article met en place le vêtement en tant que thème et perspective d'aborder la constitution de la spatialité à la maison et dans la rue. Plutôt, on indique la langue de l'habillement en tant qu'instruments qui nous permet de lire certains spatialité et bien que les vêtements définissent l'espace-temps.

Mots-clés: vêtements, maison, rue, spatialité.

\section{Risco, corte e costura}

O que são vestimentas? As vestimentas podem ser objeto ou tema geográfico? Se a resposta à primeira pergunta implica a segurança de recorrermos a dicionários e à bibliografia existente sobre roupa e moda, a segunda parece improcedente; afinal, o que a geografia teria a dizer sobre vestimentas? Comecemos por riscar a primeira questão antes de moldarmos a segunda. 
No Grande Dicionário Houaiss da Língua Portuguesa (2012), são apresentadas as seguintes definições de vestimenta: "1 peça de roupa que serve para vestir qualquer parte do corpo; vestidura; 2 roupas us. como paramento para uma cerimônia, uma liturgia etc.; traje; ‘apareceram os magistrados com sua v. solene» «comparemos a v. sacerdotal budista com a católica); 3 fig. tudo o que forma cobertura, revestimento; vestidura «a v. verde dos campos»". Toussaint-Samat (1990, p. 5) nos fornece uma definição mais refinada do termo: "Le vêtement (du latin vestire, couvrir, entourer) désigne 'tout objet improvisé ou fabriqué pour couvrir le corps humain, ceci à des fins diverses: protection, dissimulation, signe de reconnaissance .' On se vêt." ${ }^{1}$ Neste texto, seguiremos a recomendação conceitual de Guillemard de usar a palavra 'vestimentas', no plural, na primeira parte, em que expomos referências acerca deste objeto na Geografia Clássica, pois o termo no singular designa “s'il n'est pas suivi par un déterminant (vêtement de nuit, vêtement de sport etc.), une pièce particulière de l'habillement, généralement une petite chose d'appoint, veste ou chandail, qu'une femme emportera par exemple pour une sortie nocturne, en prévision de la fraîcheur de la soirée”2 (1991, p. 46). Assim, na segunda parte empregamos o termo no singular ao enfoque da "vestimenta de casa" e "vestimenta para rua". Nestas diferentes definições ressalta-se que vestimentas cobrem o corpo, mas, ao fazê-lo, ganham significados maiores que o de simples "cobertura" e expressam status, classes, grupos etários, identificações, gostos, costumes etc. Mas o que "se veste" é objeto ou tema geográfico?

Iniciamos nas linhas seguintes uma resposta para esta questão revisitando a "Geografia Clássica", na qual encontramos as vestimentas como objetos abordados por Vidal de La Blache, Sorre, Deffontaines, Ratzel e entre outros que aqui utilizamos para riscar nossa argumentação da pertinência geográfica do objeto-tema; que se complementa, na primeira parte do artigo, com referências a algumas perspectivas contemporâneas que enfocam os vieses econômicos e incursões de outras ciências sobre as espacialidades das vestimentas.

Na segunda parte da exposição, procura-se conciliar vintage e contemporâneo a partir de discussões teóricas e empíricas sobre casa-rua-vestimenta, tecidas com diálogo transdisciplinar e interpretação de dados obtidos mediante aplicação de questionário divulgado em rede social (Facebook), no qual obtivemos a somatória de 448 respondentes que 
residem em 103 municípios das cinco Regiões do Brasil e 5 residentes no exterior, até o dia 9 de maio de 2015. O questionário foi disponibilizado no dia 31 de março de 2015 e permanece on-line no endereço https://www. facebook.com/carlosedumaia para recebimento de respostas de pessoas na faixa de 15 a 74 anos de idade.

\section{0 clássico lhe cai bem}

Embora pareça estranho propor a temática das vestimentas na geografia que, nas ciências, está associada a pesquisas nos campos da história (Toussaint-Samat, 1990; Riello, 2013; Örmen, 2011; Hansen, 1956; James, 1989; Nery, 2009), da sociologia (Alberoni, 1982; Godart; 2012), da filosofia (Simmel, 2013) e da psicologia (Alcântara, 2010; Sigurta, 1982), quando começamos nosso "trabalho arqueológico" e "escavamos" os clássicos, tivemos a grata surpresa de verificar a existência de "geografias das vestimentas" entre eles. Vidal de La Blache $(1902,1941)$ tratou as vestimentas como um dos indicadores dos gêneros de vida, ou melhor, na qualidade de objeto "dans lequel s>expriment les habitudes, les dispositions et les préférences de chaque groupe" ${ }^{3}$ (1902, p. 14). Neste sentido, exemplifica: "Le matériel que le Kirghz a créé à l'usage de sa vie de déplacements périodiques, la forme de sa tente, de ses vêtements, réalisent un ensemble où tout se tient, comme la personnification d'un genre de vie"4 (1941, p. 201; grifo nosso).

A tradição francesa de valorizar a análise "objetiva" das vestimentas relativamente ao gênero de vida também ocorreu em Sorre (2002-2003, 1947) ao discutir as relações ecológicas e econômicas das vestimentas, notando que a geografia da "vestimenta é inseparável da geografia das indústrias têxteis” (2002-2003, p. 193). Especificamente acerca das relações ecológicas, Sorre comentava as influências climáticas e a função de proteção contra doenças provocadas por parasitas que entrariam no organismo através da pele; ou, em casos opostos, as próprias vestimentas abrigariam parasitas como ácaros, pulgas e piolhos. De qualquer modo, as vestimentas promoveriam um "isolamento artificial do homem” (Sorre, 1947, p. 61).

Sem negar a dimensão das influências que a natureza exerce sobre as vestimentas, o polêmico geógrafo colonialista Hardy, em sua "geografia psicológica", trouxe a discussão de como as vestimentas nos possibilitam "ler" indivíduos e coletividades: 
pour la connaissance de l'individu, le vêtement offre un document de premier ordre, et la diction « L'habit ne fait pas le moine » est d'une exactitude tout approximative. Mais ce qui est vrai d'un individu l'est bien plus encore d'une collectivité : le vêtement devient alors une sorte d'uniforme, dont les modifications successives coïncident presque toujours avec des mouvements généraux de la vie sociale et dont les caractères dominants extériorisent certains aspects du tempérament commun. ${ }^{5}$ (Hardy, 1939, p. 46)

Sua ideologia colonialista manifesta-se explicitamente quando profere: "Retenons d'abord ce qu'on pourrait appeler une signification indirecte. Par exemple, le vêtement, dans bien des cas, constitue une distinction d'origine ethnique ou nationale [...]. Par-là, le vêtement évoque indirectement les influences que la nature et les occupations courantes peuvent exercer sur les mentalités”6 (Hardy, 1939, p. 46). Mesmo com esse lado ideológico nefasto, Hardy pioneiramente apontou questões relacionadas à geografia das vestimentas que adentram na simbologia, na estética, na moral e na sua relação com a corporeidade:

Ce qui ressort aussi de l'allure générale du vêtement, c'est la joie de vivre ou la morne résignation au destin. Ici, riches ou pauvres, citadins ou paysans, tous éprouvent du plaisir à s'habiller, recherchent l'agrément et l'éclat, rivalisent d'aimable coquetterie [...]. En somme, le vêtement nous renseigne sur les influences, mais il nous permet en même temps de mesurer le degré de plasticité d'un groupement, son attachement aux traditions locales, aux coutumes religieuses, à tout ce qui constitue l'armature de l'âme collective [...]. Si, après cet échantillonnage de faits significatifs, on avait encore à prouver la valeur psychologique du vêtement, il suffirait sansdoute rappeler qu'il a toujours existé une 'morale du vêtement'. [...] Bien mieux, il y a une 'politique du vêtement', et qu'il serait bien intéressant d'étudier dans le temps et dans l'espace. Il ne s'agit pas seulement de lois somptuaires [...] Il s'agit surtout des décisions qui, par l'intermédiaire des usages vestimentaires, tendent à incliner dans un sens déterminé les habitudes morales des peuples. ${ }^{7}$ (1939, p. 51-54)

Os vínculos colonialistas de Hardy relegaram-no quase ao total esquecimento e sua obra La Géographie Psychologique foi severamente criticada numa resenha de Demangeon, em que o autor atribuiu ironicamente a Hardy, "sinon l'invention du moins la découverte d'une nouvelle science laquelle il [Hardy] a donné le nom de Géographie psychologique” (1940, p. 134). Demangeon advertiu que, para Hardy, a geografia psicológica versava sobre a "psicologia coletiva”, estudada nos "gestos habituais" 
que eram perpassados por "significação mental e moral”, entre os quais se encontravam as vestimentas. Para Demangeon, boa parte da "geografia psicológica" estava englobada nos estudos de geografia humana e etnologia, sendo assim por ele rechaçada em sua própria essência enquanto geografia.

A tradição francófona clássica de inserir as vestimentas no contexto do gênero de vida e vê-las como objeto de estudo foi seguida por Deffontaines, que teve enorme impacto na institucionalização da geografia acadêmica brasileira. No trabalho intitulado L'Homme et L'Hiver au Canada, o autor descreveu a influência do inverno na "geografia das vestimentas" no Canadá colonial, expondo como hábitos franceses foram adotados e adequados àquela realidade, na qual, não raro, o frio causava morte: "Pour se défendre, il fallait avoir des vêtements suffisamment chauds et nombreux; l'habillement constituait un capital de haute valeur"9 (Deffontaines, 1957, p. 105). O porquê das vestimentas se tornarem capital foi assim explicado: "Les vêtements restèrent longtemps chers et constituaient la preuve de la richesse; au début, ils arrivaient de France, mais en quantité insuffisante [...] Il y eut un important marché clandestin de tissu"10 (Deffontaines, 1957, p. 105). O autor relatava ainda as vestimentas típicas de inverno para homens - "un pardessus court, doublé en peau de mouton à large col de fourrure" - e mulheres - "de gros jupons de laine superposés”11 (Deffontaines, 1957, p. 105). Outro fato interessante apontado por Deffontaines referia-se ao trabalho feminino domiciliar no aproveitamento dos fios dos trajes já rotos, produzindo-se tecidos coloridos chamados catalognes. Aliás, o trabalho de costura era fundamental ao aprendizado feminino naquela época, sendo exarado no seguinte ditado: "qu’il ne se mariait créature (femme) qui ne sût tisser le drap". ${ }^{12}$ Destarte, o trabalho feminino "était un élément capital de la lutte contre l'hiver, au point que, parfois, on se mariait pour avoir des vêtements chauds; un proverbe dit: "Un homme sans femme ne tient pas l'hiver"13 (Deffontaines, 1957, p. 103). Acerca das crianças naquele contexto, o autor notava que elas permaneciam "enclausuradas" no inverno e quase não saiam, pois as vestimentas quentes eram mobilizadas para os homens (Deffontaines, 1957, p. 105).

Ainda nas lentes que focam as influências do meio sobre o homem e os impactos disso nas vestimentas, o geógrafo anarquista Reclus exarou um pensamento não muito distinto daquele que encontraremos em Ratzel: 
As necessidades da existência determinam um modo de alimentação que varia segundo as regiões; da mesma forma, a nudez ou o vestuário, o acampamento ao ar livre ou os diversos tipos de habitações - grutas e tetos de folhas, cabanas e casas - agem e reagem sobre a maneira de sentir e pensar, criando assim, em grande parte, aquilo que se chama “civilização”. (Reclus, 1985, p. 57; grifo nosso)

Dessa maneira, revirando-se rapidamente o baú da geografia alemã encontramos as vestimentas sendo tratadas por Ratzel em parâmetros não muito diferentes daqueles seus vizinhos franceses. Na breve incursão de Ratzel que localizamos acerca da geografia das vestimentas, ele a fez a partir de comentários sobre o patrimônio material e espiritual da civilização, em que o primeiro (patrimônio material) teria certa primazia sobre o segundo (patrimônio espiritual), que surgiria como "um luxo após a satisfação das necessidades básicas” (1990, p. 135-136). De acordo com Ratzel, o que importa na base material da civilização, a ponto de favorecer o seu desenvolvimento, não é propriamente a riqueza da natureza em substâncias, mas sim os estímulos à engenhosidade humana. É com base neste princípio que ele abordou a questão do vestir, ou seja, associando-o às forças naturais (calor) que o tornariam algo "tão mais simples" na zona tropical. Paralelamente, Ratzel examinou a decadência do patrimônio de uma civilização quando em contato com outra, fosse de uma cultura "superior" impelida a absorver certos costumes de uma "inferior", ou fosse de uma "superior" que impôs sua "arte" a uma "inferior", e exemplifica:

Em relação à América setentrional, Schoolcraft foi o primeiro a acenar à rápida decadência a que estava sujeita qualquer atividade industrial dos indígenas com a introdução pelos brancos de instrumentos, vasilhames, vestimentas etc. mais adaptados aos seus objetivos. (Ratzel, 1990, p. 139; grifo nosso)

Neste rápido recorte dos clássicos nota-se que tomar as vestimentas como objeto não é algo novo na geografia, embora isto seja negligenciado ou subdimensionado nas tendências contemporâneas; exceto nos estudos da instância econômica das indústrias de vestimentas em trabalhos relacionados aos impactos da globalização (Smith, Pickles, Begg et al., 2005; Scott, 2006; Eraydin; Erendil, 1999; Tokatli, 2014; Tokatli; Kizilgün, 2004), à divisão espacial do trabalho (Smith, Pickles, Begg et al., 2005; Scott, 2006; Tokatli; Kizilgün, 2004) e à relação de gênero na dinâmica produtiva (Eraydin; Erendil, 1999). 
Todavia, a dimensão espacial das vestimentas é notada mesmo em escritos de não geógrafos como encontramos, por exemplo, em Steele (2013) ao comentar sobre a rede de indústrias implicada na moda, que se estende da produção de matérias-primas, passando pela confecção, à distribuição e à comercialização. Já Riello adverte sobre os usos das vestimentas em espaços públicos na Idade Média como forma de diferenciação social, de modo que "a cidade era também o local onde se podia ostentar novos trajes, especialmente para as elites, que optavam cada vez mais por residir dentro dos muros urbanos" (2013, p. 19). Örmen igualmente salienta o caráter urbano nas raízes da moda: "Pendant des siècles, la mode demeura un phénomène urbain. Il ne faut pas oublier que les villes n'étaient pas ce qu'elles sont aujourd'hui : une très faible partie de la population y vivait"14 (2011, p. 11). Monteiro (2009) nos indica relações entre corporeidade, espacialidade e subjetivação presentes no próprio ato de comprar roupa. James (1989) e Nery (2009) expõem como certas vestimentas relacionadas a um grupo marginalizado e segregado espacialmente (punks) entra intencionalmente no "circuito da moda" e se populariza nas ruas. Alcântara atenta para a relação roupa-cenário na qual, atualmente, o segundo sobressai: "o criminoso de terno e gravata, durante o seu julgamento, o cenário fala quem ele é” (2010, p. 22). Dado que geógrafos clássicos e não geógrafos têm falado de geografias das vestimentas, apresentamos uma questão para ser aprofundada pelos geógrafos atuais interessados em outros "estilos".

\section{Nova coleção}

Como demonstraram os clássicos, vestimentas traduzem gêneros de vida, necessidades básicas, patrimônio e prazeres de determinado grupo; ou ainda, como indicam trabalhos contemporâneos, sua produção relaciona-se à globalização e à atual divisão espacial do trabalho, bem como a existência de relações de gênero na sua confecção. Todavia, gostaríamos de apontar outra questão que pode ser explorada na geografia das vestimentas: a distinção de seu uso em casa e na rua, o que discutimos inicialmente a partir das análises da casa e da rua feitas por DaMatta em que o autor as define como espaços que "contêm visões de mundo ou éticas particulares” (1997, p. 47) e complementa:

Embora existam muitos brasileiros que falam uma mesma coisa em todos os espaços sociais, o normal - o esperado e o legitimado - é 
que casa, rua e outro mundo demarquem fortemente mudanças de atitudes, gestos, roupas, assuntos, papéis sociais e quadro de avaliação da existência em todos os membros da sociedade. (DaMatta, 1997, p. 48; grifo nosso)

Destarte, casa e rua possuem códigos éticos diferenciados e "certas coisas só podem ser feitas em casa e, mesmo assim, dentro de alguns dos seus espaços" (DaMatta, 1997, p. 50). Isso significaria dizer que "não posso transformar a casa na rua e nem a rua na casa impunemente" (DaMatta, 1997, p. 54), tampouco que a oposição entre esses espaços seja estática ou absoluta. Entretanto,

a casa distingue esse espaço de calma, repouso, recuperação e hospitalidade, enfim tudo aquilo que define a nossa ideia de "amor", "carinho" e "calor humano", a rua é um espaço definido precisamente ao inverso. Terra que pertence ao "governo" ou ao "povo" e que está sempre repleta de fluidez e movimento. A rua é um local perigoso. (DaMatta, 1997, p. 57)

Bollnow, por sua vez, nota que "o indivíduo, ao confiar-se à rua, é tomado por esse trânsito [supra-individual e neutro]; é por ele absorvido. Se em casa ele era um indivíduo, na rua se torna anônimo” (2008, p. 110). Assim, numa visão bastante romântica, para Bollnow, a rua se apresenta como o espaço do "desabrigo" e da "exposição", já em casa tem-se "o âmbito do silêncio e da paz, no qual o homem pode desligar sua atenção constantemente em alerta a uma possível ameaça, um espaço em que o homem pode se recolher e relaxar" (2008, p. 139). Maia igualmente analisa a casa numa perspectiva relacional comparativamente ao "mundo exterior". Sem negar que a casa forneça abrigo, a autora compreende também a casa como lugar de reprodução das desigualdades sociais. Assim, esta (a casa)

costuma carregar em si a possibilidade de aconchego, de abrigo, de integração frente a um mundo caótico [...]. Sentir-se em casa, desta forma, significa estabelecer uma relação de identidade com o objeto arquitetônico, é "lugarizá-lo" a partir das relações estabelecidas com os demais sujeitos sociais, sejam aqueles que partilham do mesmo espaço, sejam aqueles que se posicionam no "mundo exterior". (2013, p. 2)

A autora, tal como DaMatta (1997), sublinha necessidade de considerar a casa a partir de "necessária referência a um tempo, a um espaço, a uma cultura” (Maia, 2013, p. 2). Neste sentido, profere: “A casa tem 'voz' 
e 'alma'. Expressa um tempo, uma cultura. Reflete a dinâmica econômica, as desigualdades sociais. Diz muito da política, em sua acepção mais ampla. É território e lugar, espaço de afagos ou de dissensos” (2012, p. 340). Se Maia e DaMatta concordam que casa e rua devem ser consideradas numa perspectiva relacional com outros espaços, em sua temporalidade e cultura, Maia nas suas pesquisas sobre "casa-abrigo", "casa-vitrine" e "casa-bazar" estabelece uma clivagem com DaMatta, pois, para este, "em casa, sabemos todos - como bons brasileiros que somos -, não devemos comprar, vender ou trocar. O comércio está excluído da casa como o Diabo se exclui de Deus" (DaMatta, 1984, p. 27). Maia, por outro lado, em pesquisas mais contemporâneas demonstra a funcionalidade da casa como "bazar”, o que pode ocorrer em “"puxadinhos' ou 'sobradinhos', nas garagens, o que não impede que, em certos casos, também venham a ser desenvolvidas no interior da própria residência [...]” (Maia, 2013, p. 11; grifo nosso).

Aqui temos um ponto interessante de investigação na geografia das vestimentas que pode ser respaldado na teoria dos circuitos superior e inferior da economia de Santos (1979), no qual a casa "loja de roupa", "circuito inferior", se relacionaria com os espaços produtivos do "circuito superior” para adquirir matéria-prima. Todavia, ainda permaneceríamos num viés econômico, mesmo perpassado pela relação espaço-tempo-cultura. Mas a casa (e a rua), como a própria Maia $(2012,2013)$ ressalta é plena de aspectos simbólicos e pretendemos destacá-los neste momento. Particularmente, nos interessa demonstrar alguns aspectos relacionados à geografia da vestimenta de casa e de vestimenta para rua.

A utilização das preposições "de" e "para" já é intencional no sentido de marcar espacialidades distintas. Por "de" evidenciamos "o ponto de partida, originário de" (Faria, 1962, p. 277), já com "para” queremos ressaltar o sentido de "através de, diante de, ao longo de" (Faria, 1962, p. 718). De outro modo, as vestimentas de casa e para rua denotam modos como constituímos espacialidades no abrigo e do qual partimos com destino ao mundo exterior, ambos plenos de contradições, conflitos e dilemas. A leitura das vestimentas nos permite perceber valores, modos de ser, fetiches, aspirações, normatividades, estéticas etc. espacializadas na casa e na rua, que vão da casa para a rua, que vêm da rua para a casa; pois “o vestuário [...] 'fala'. Fala o facto de eu me apresentar no escritório de manhã com uma gravata normal de riscas, fala o facto de a substituir inesperadamente por uma gravata psicodélica, fala o facto de ir à reunião 
do conselho de administração sem gravata” (Eco, 1982, p. 15). Se o vestuário "fala", o que pode ser dito através das vestimentas de casa e para rua varia. Sennet observa isto na sociedade francesa e inglesa do século XVIII, onde "no lar [...] roupas folgadas e simples ganhavam a preferência de todas as classes [...]. Na rua, por contraste, eram usados trajes que marcavam de modo mais reconhecível o lugar de quem os vestia...” (1998, p. 91). Sennet assim esclarece esta geografia da vestimenta para rua e de casa no século XVIII:

Em casa, a roupa combinava com o corpo e suas necessidades; nas ruas, entrava-se dentro de roupas cujo propósito era tornar possível às outras pessoas agirem como se soubessem quem se era. A pessoa se tornava uma figura dentro de uma paisagem armada; o propósito das roupas não era o de assegurar a uma pessoa saber com quem estava tratando, mas antes o de lhe permitir comportar-se como se estivesse segura. (1998, p. 92)

Em nossa pesquisa, quando perguntamos "Como geralmente você se veste para ficar em casa?" boa parte dos respondentes confirmou que a vestimenta de casa ainda hoje combina com o corpo e suas necessidades, sendo citadas as seguintes peças de vestimenta de casa: short 131 vezes, camiseta 103 vezes, pijama 91 vezes, bermuda 59 vezes, chinelo 57 vezes, blusa 52 vezes, vestido 34 vezes, camisa 24 vezes, regata 22 vezes, cueca 19 vezes, calça 16 vezes, camisola 15 vezes, moletom 10 vezes, calcinha 6 vezes, sandália 6 vezes. Paralelamente às peças de vestimenta de casa, houve ainda referências à maneira de vestir-se (confortavelmente 109 vezes, à vontade 22 vezes, de modo simples 17 vezes, básico 12 vezes, como mendigo 3 vezes) e ao estado de conservação e estética da vestimenta de casa (roupas velhas 68 vezes; leves 26 vezes; soltas 11 vezes; rasgadas 6 vezes; e frescas 4 vezes). Citou-se igualmente que a vestimenta de casa se adequa à estação do ano e com as condições climáticas predominantes na localidade e que, em alguns casos, já foi "roupa de sair". A permissividade da nudez também foi registrada nas respostas. Poucos respondentes demonstraram maiores preocupações com a maneira de vestir-se em casa; ou seja, parece predominar em casa aquele "desligamento do estado de atenção” como já mencionado por Bollnow. Seguem algumas respostas: 


\begin{tabular}{|c|c|c|c|c|}
\hline \begin{tabular}{|l|} 
Local de \\
residência
\end{tabular} & Idade & Sexo & $\begin{array}{l}\text { Estado } \\
\text { civil }\end{array}$ & $\begin{array}{l}\text { Como geralmente você se } \\
\text { veste para ficar em casa? }\end{array}$ \\
\hline Catalão (GO) & 49 & masculino & solteiro & $\begin{array}{l}\text { Short e camiseta no calor... no } \\
\text { inverno agasalhado. }\end{array}$ \\
\hline Jataí (GO) & 26 & masculino & solteiro & $\begin{array}{l}\text { Roupas íntimas ou nu, se } \\
\text { estou só. Bermuda, camiseta e } \\
\text { chinela se tenho companhia. }\end{array}$ \\
\hline $\begin{array}{l}\text { Juiz de Fora } \\
\text { (MG) }\end{array}$ & 25 & masculino & solteiro & $\begin{array}{l}\text { Confortavelmente. De acordo } \\
\text { com o tempo, com mais ou } \\
\text { menos roupa. Geralmente com } \\
\text { roupas que não uso mais para } \\
\text { sair. }\end{array}$ \\
\hline Posse (GO) & 28 & masculino & solteiro & Cueca ou pelado. \\
\hline Goiânia (GO) & 27 & feminino & solteira & $\begin{array}{l}\text { Roupas velhas, rasgadas, } \\
\text { manchadas, calcinha que já } \\
\text { não tem mais elástico, e o mais } \\
\text { importante: peças frescas, } \\
\text { curtas e cavadas por conta do } \\
\text { calor. }\end{array}$ \\
\hline $\begin{array}{l}\text { Governador } \\
\text { Mangabeira } \\
\text { (BA) }\end{array}$ & 27 & feminino & solteira & $\begin{array}{l}\text { Confortavelmente com roupas } \\
\text { de mendiga rsrs. }\end{array}$ \\
\hline $\begin{array}{l}\text { Rio de Janeiro } \\
(\mathrm{RJ})\end{array}$ & 34 & feminino & $\begin{array}{l}\text { União } \\
\text { estável }\end{array}$ & $\begin{array}{l}\text { Uso vestidos que comprei por } \\
20 \text { reais, ou vestidos velhos, } \\
\text { descalça e sem roupa íntima. } \\
\text { No Rio faz muito calor. }\end{array}$ \\
\hline $\begin{array}{l}\text { Juiz de Fora } \\
\text { (MG) }\end{array}$ & 19 & masculino & solteiro & $\begin{array}{l}\text { Camisa e bermuda/calça } \\
\text { simples dependendo da } \\
\text { estação do ano ou do tempo no } \\
\text { dia a dia. }\end{array}$ \\
\hline $\begin{array}{l}\text { Juiz de Fora } \\
\text { (MG) }\end{array}$ & 22 & masculino & solteiro & $\begin{array}{l}\text { Roupa fresca e confortável. } \\
\text { Geralmente utilizo roupas que } \\
\text { já usei para sair, mas ficaram } \\
\text { "batidas". }\end{array}$ \\
\hline $\begin{array}{l}\text { Aparecida de } \\
\text { Goiânia (GO) }\end{array}$ & 27 & masculino & solteiro & $\begin{array}{l}\text { Roupas básicas: bermuda, } \\
\text { camiseta ou regata e sandália } \\
\text { de dedo. }\end{array}$ \\
\hline Goiânia (GO) & 31 & feminino & solteira & $\begin{array}{l}\text { Short e camiseta. Mas, se } \\
\text { morasse sozinha, andaria } \\
\text { pelada numa boa! }\end{array}$ \\
\hline $\begin{array}{l}\text { Campo } \\
\text { Grande (MS) }\end{array}$ & 34 & feminino & casada & $\begin{array}{l}\text { No verão, com vestidos curtos, } \\
\text { soltos e confortáveis. No } \\
\text { inverno, moletom. }\end{array}$ \\
\hline
\end{tabular}




\begin{tabular}{|c|c|c|c|c|}
\hline $\begin{array}{l}\text { Local de } \\
\text { residência }\end{array}$ & Idade & Sexo & $\begin{array}{l}\text { Estado } \\
\text { civil }\end{array}$ & $\begin{array}{l}\text { Como geralmente você se } \\
\text { veste para ficar em casa? }\end{array}$ \\
\hline Palmas (TO) & 48 & feminino & divorciada & $\begin{array}{l}\text { Não gosto de roupa, mas } \\
\text { como sou obrigada usar, uso } \\
\text { shortinho e blusinhas leves. }\end{array}$ \\
\hline Goiânia (GO) & 28 & masculino & casado & $\begin{array}{l}\text { Cueca e regata. Não tenho } \\
\text { ar-condicionado e vivo no } \\
\text { cerrado. }\end{array}$ \\
\hline $\begin{array}{l}\text { Balneário } \\
\text { Camboriú } \\
\text { (SC) }\end{array}$ & 36 & feminino & solteira & $\begin{array}{l}\text { Geralmente coloco um short, } \\
\text { blusa e chinelo ou um vestido } \\
\text { caso seja verão, se for inverno, } \\
\text { calça confortável ou jeans, e } \\
\text { uma blusa. }\end{array}$ \\
\hline $\begin{array}{l}\text { Blumenau } \\
\text { (SC) }\end{array}$ & 53 & feminino & divorciada & $\begin{array}{l}\text { De forma despojada e } \\
\text { confortável, incluindo o direito } \\
\text { de ficar de pijama ou camisola. }\end{array}$ \\
\hline $\begin{array}{l}\text { Rio de Janeiro } \\
(\mathrm{RJ})\end{array}$ & 30 & feminino & solteira & $\begin{array}{l}\text { Quando está muito quente só } \\
\text { biquíni. Geralmente short e } \\
\text { blusa ou vestido. }\end{array}$ \\
\hline Manaus (AM) & 25 & feminino & solteira & $\begin{array}{l}\text { Como nosso clima é quente, } \\
\text { é impossível não vestir uma } \\
\text { camiseta e uma bermuda } \\
\text { confortável... }\end{array}$ \\
\hline Natal (RN) & 22 & masculino & solteiro & $\begin{array}{l}\text { O mais confortável possível } \\
\text { (incluindo não se vestir). }\end{array}$ \\
\hline $\begin{array}{l}\text { Itanhaém } \\
\text { (SP) }\end{array}$ & 50 & feminino & divorciada & $\begin{array}{l}\text { Confortável, mas pronta para } \\
\text { sair se necessário... calça ou } \\
\text { bermuda e camiseta com tênis } \\
\text { ou sandálias. }\end{array}$ \\
\hline $\begin{array}{l}\text { Barcelona- } \\
\text { Catalunya- } \\
\text { Espanha }\end{array}$ & 29 & feminino & solteira & $\begin{array}{l}\text { Roupas confortáveis e quando } \\
\text { estou no Brasil e faz calor, } \\
\text { nenhuma! }\end{array}$ \\
\hline $\begin{array}{l}\text { Rio do Sul } \\
\text { (SC) }\end{array}$ & 28 & feminino & casada & $\begin{array}{l}\text { De maneira mais simples, mas } \\
\text { pensada! }\end{array}$ \\
\hline $\begin{array}{l}\text { Santa Maria } \\
(\mathrm{RS})\end{array}$ & 20 & masculino & solteiro & $\begin{array}{l}\text { Confortavelmente, mas não } \\
\text { muito diferente de como } \\
\text { estaria fora de casa. }\end{array}$ \\
\hline $\begin{array}{l}\text { Juiz de Fora } \\
\text { (MG) }\end{array}$ & 19 & feminino & solteira & Sempre bem arrumada. \\
\hline
\end{tabular}

Fonte: Maia, pesquisa on-line https://www.facebook.com/carlosedumaia, 2015. 
No questionário também perguntamos "Que peça de roupa você usa em casa e NÃO USARIA na rua?” Nesta pergunta, ratifica-se que, no espaço-tempo da casa, a vestimenta combina com o corpo e suas necessidades, com características de simplicidade e despojamento; pois a casa, como lugar, nos remete à intimidade, à privacidade, ao aconchego e a relações de expressão da corporeidade e espacialidades distintas daquelas que assumimos na rua, na maioria das vezes, enquanto "atores". Eco (1982) observa que a linguagem da vestimenta, assim como a linguagem oral ou escrita, pode permitir certas variantes, embora condicionada por fortes códigos, o que se faz presente mesmo na vestimenta de casa em oposição àquela para a rua. Assim, como peça de vestimenta que não se usaria na rua, o pijama foi mais citado, em 151 respostas, havendo ainda referências à camisola (30 respostas), cueca (11 respostas), moletom (4 respostas) e calcinha (4 respostas). Boa parte dos respondentes não citou propriamente uma peça de roupa específica, mas assim como na pergunta anteriormente comentada o seu estado (roupa velha 59 vezes; roupa rasgada 25 vezes; roupa desbotada 10 vezes), ou a sua estética (roupa de dormir 29 vezes; roupa curta 69 vezes; roupa transparente 13 vezes). Vejamos alguns exemplos:

\begin{tabular}{|c|c|c|c|c|}
\hline $\begin{array}{l}\text { Estado } \\
\text { civil }\end{array}$ & $\begin{array}{l}\text { Orientação } \\
\text { sexual }\end{array}$ & Sexo & Idade & Respostas \\
\hline solteiro & homossexual & masculino & 24 & $\begin{array}{l}\text { Não usaria pijama na rua, } \\
\text { isso por conta da "repressão } \\
\text { social" existente com o } \\
\text { modo de vestir-se e se } \\
\text { comportar fora de nossas } \\
\text { casas. }\end{array}$ \\
\hline solteira & heterossexual & feminino & 17 & $\begin{array}{l}\text { Quase todos. Porque moro } \\
\text { no ACRE, aqui as pessoas } \\
\text { te olham de cima a baixo } \\
\text { independentemente de onde } \\
\text { você esteja. Acredito que sair } \\
\text { de camisola, blusão da época } \\
\text { da } 1^{\text {a }} \text { guerra mundial ou um } \\
\text { short se descosturando, não } \\
\text { atrairia um pensamento bom } \\
\text { ao meu respeito. Kk. }\end{array}$ \\
\hline
\end{tabular}




\begin{tabular}{|c|c|c|c|c|}
\hline $\begin{array}{l}\text { Estado } \\
\text { civil }\end{array}$ & $\begin{array}{l}\text { Orientação } \\
\text { sexual }\end{array}$ & Sexo & Idade & Respostas \\
\hline solteira & heterossexual & feminino & 40 & $\begin{array}{l}\text { Camisola. Considero } \\
\text { socialmente inadequado. }\end{array}$ \\
\hline solteiro & homossexual & masculino & 24 & $\begin{array}{l}\text { Não usaria somente cueca } \\
\text { para ir à rua porque } \\
\text { socialmente é considerada } \\
\text { como uma roupa íntima. }\end{array}$ \\
\hline casada & bissexual & feminino & 27 & $\begin{array}{l}\text { Calcinha e camiseta. Porque } \\
\text { eu seria presa por atentado } \\
\text { ao pudor. }\end{array}$ \\
\hline solteira & heterossexual & feminino & 37 & $\begin{array}{l}\text { Short velho e blusa larga. } \\
\text { São roupas confortáveis } \\
\text { para ficar em casa, porém } \\
\text { inapropriadas para o uso em } \\
\text { lugares públicos. }\end{array}$ \\
\hline solteira & heterossexual & feminino & 21 & $\begin{array}{l}\text { Roupa velha, porque não } \\
\text { condiz com o fim. }\end{array}$ \\
\hline solteiro & heterossexual & masculino & 22 & $\begin{array}{l}\text { Roupas rasgadas não usaria } \\
\text { porque não há necessidade, } \\
\text { tendo em vista que possuo } \\
\text { roupas em bom estado de } \\
\text { conservação. }\end{array}$ \\
\hline casada & heterossexual & feminino & 34 & $\begin{array}{l}\text { Não uso nada que me } \\
\text { incomode, ou que eu } \\
\text { considere inapropriado } \\
\text { para o meu corpo e minha } \\
\text { idade, mesmo que seja para } \\
\text { ficar em casa. Portanto, } \\
\text { não há uma peça de roupa } \\
\text { especifica que eu me permita } \\
\text { usar em casa, mas não } \\
\text { admitiria usar na rua. Mas } \\
\text { faço ressalvas ao estado de } \\
\text { conservação das roupas. } \\
\text { Vestimentas um tanto } \\
\text { desgastadas, desbotadas } \\
\text { ou com manchas não saem } \\
\text { para a rua, independente do } \\
\text { destino ou ocasião. }\end{array}$ \\
\hline
\end{tabular}




\begin{tabular}{|c|c|c|c|c|}
\hline \begin{tabular}{|l|}
$\begin{array}{l}\text { Estado } \\
\text { civil }\end{array}$ \\
\end{tabular} & $\begin{array}{l}\text { Orientação } \\
\text { sexual }\end{array}$ & Sexo & Idade & Respostas \\
\hline solteiro & heterossexual & masculino & 28 & $\begin{array}{l}\text { Todas, pois de modo geral } \\
\text { as roupas escolhidas para } \\
\text { ficar em casa são usadas já } \\
\text { há muito tempo, ou já não } \\
\text { se adéquam para sair, como } \\
\text { desbotamento de cores, por } \\
\text { exemplo. }\end{array}$ \\
\hline namorando & heterossexual & masculino & 41 & $\begin{array}{l}\text { Bermudas mais antigas e } \\
\text { blusas mais desbotadas pelo } \\
\text { tempo. Porque acho que } \\
\text { na rua você tem que estar } \\
\text { melhor vestido. }\end{array}$ \\
\hline solteira & heterossexual & feminino & 27 & $\begin{array}{l}\text { Peças que sejam de roupas } \\
\text { de dormir, pelo simples fato } \\
\text { de que as pessoas se chocam } \\
\text { socialmente e não estão } \\
\text { acostumadas. }\end{array}$ \\
\hline solteiro & homossexual & masculino & 24 & $\begin{array}{l}\text { Shorts curtos, para evitar } \\
\text { gente mexendo comigo. }\end{array}$ \\
\hline solteira & bissexual & feminino & 36 & $\begin{array}{l}\text { Roupas muito curtas e } \\
\text { muito decotadas... querer eu } \\
\text { quero... mas o corpo já não } \\
\text { colabora mais... :( }\end{array}$ \\
\hline solteira & heterossexual & feminino & 29 & $\begin{array}{l}\text { Transparências e roupas } \\
\text { curtas. Para o trabalho não } \\
\text { são adequadas. }\end{array}$ \\
\hline
\end{tabular}

Fonte: Maia, pesquisa on-line https://www.facebook.com/carlosedumaia, 2015.

Apesar de a maioria das pessoas estabelecer restrições ao uso da vestimenta de casa na rua, houve 33 respondentes que disseram "nenhuma”, entre os quais, alguns fizeram certas observações: "Nenhuma. Saio com qualquer roupa, dependendo da ocasião" (Solteira, heterossexual, feminino, 23 anos). "Nenhuma. As roupas que geralmente uso em casa são adequadas para sair” (Solteira, heterossexual, feminino, 36 anos). "Nenhuma. Não vejo problema em sair na rua mal arrumada às vezes" (Solteira, bissexual, feminino, 19 anos). "Nenhuma, porque não me preocupo com o julgamento" (Solteiro, bissexual, masculino, 25 anos). Particularmente essas respostas demonstram aquele preceito estabelecido por 
Goffman de que "qualquer estado de vestuário só é apropriado ou não em termos de outras evidências disponíveis quanto à alocação de envolvimento do indivíduo e, por isso, sua orientação à ocasião social e seus ajuntamentos" (2010, p. 229). Nesse caso, como vimos em determinada resposta, há quem se vista adequado para "sair" e quem seja alheio aos possíveis comentários num ajuntamento. ${ }^{15}$ Assim, considerando tanto os que não têm restrições ao uso da vestimenta de casa como vestimenta para rua, quanto aqueles que as possuem, concordamos com Goffman quando afirma que "podemos esperar e predizer muita variação quanto ao que será considerado uma roupa permissível” (2010, p. 229).

Se hoje em dia os códigos das vestimentas de casa e para rua são fortes, em antanho estes eram mais ainda. Sennet, acerca disso, adverte que, em Paris e Londres de meados do século XVIII, poder-se-ia ler o tipo de trabalho "a partir das roupas específicas, adotadas pelos ofícios, bem como se reconheceria o status de um trabalhador dando-se uma olhada rápida em certas fitas e botões que usava” (1998, p. 89). Já não vemos tanto nas ruas as vestimentas distinguindo ofícios, exceto naqueles que as exigem na qualidade de uniformes (limpeza urbana, segurança, correios, forças armadas e alguns técnicos, por exemplo) ou como norma de conduta e apresentação (advogados, executivos). Parece-nos que o "corpo manequim" comentado por Sennet se travestiu de outros significados, pois, como nota o próprio Sennet, "hoje em dia, um homem na rua pode distinguir as pessoas pobres das de classe média apenas ao vê-las e, com uma precisão um pouco menor, as pessoas ricas das da classe média” (1998, p. 89). Atente-se que não só o que se veste na rua distingue as "classes", mas também onde se compra o que se veste e mesmo o ato de sair à rua para comprar vestimentas.

Nas respostas percebemos ainda variabilidade nas "ocasiões firmes e frouxas", conforme definição de Goffman. Cabe advertir que o autor define "situação" como aquele "ambiente espacial completo em que ao o adentrar uma pessoa se torna um membro do ajuntamento que está presente, ou que então se constitui. As situações começam quando o monitoramento mútuo ocorre, e prescrevem quando a penúltima pessoa sai" (Goffman, 2010, p. 28). Consideramos que situações de "ajuntamento" na exterioridade da casa ainda constituem espacialidade-corporeidade-figural-de-manequim, bem como as racionalizações sobre a frouxidão ou a firmeza variam de acordo com as implicações orientacionais da exposição 
(há quem se sujeite ao controle situacional, há quem seja alheio e ainda quem o questione). De um modo geral, os resultados da pesquisa indicam alguns locais com maior firmeza em todas as faixas etárias abrangidas na pesquisa, especialmente boates/bares, shopping centers, trabalho e instituições de ensino, havendo variância de acordo com os contextos situacionais que os sujeitos mais se expõem em cada faixa de idade. Destarte, proporcionalmente, a vigilância sobre como alguém se veste para ir a bares, boates e instituições de ensino, é mais significante na faixa etária entre os 15 e 29 anos. O local de trabalho aparece como espaço-tempo de pouca frouxidão principalmente a partir dos 20 anos de idade. A casa, a rua, as instituições religiosas e os transportes públicos, proporcionalmente, assumem significância intermediária na maior parte das faixas etárias entre aqueles espaços-tempos de maior firmeza e pouca frouxidão (boates/bares, shopping centers, trabalho e instituições de ensino) e os de maior frouxidão e pouca firmeza (praia e clubes), conforme nota-se nos gráficos a seguir:

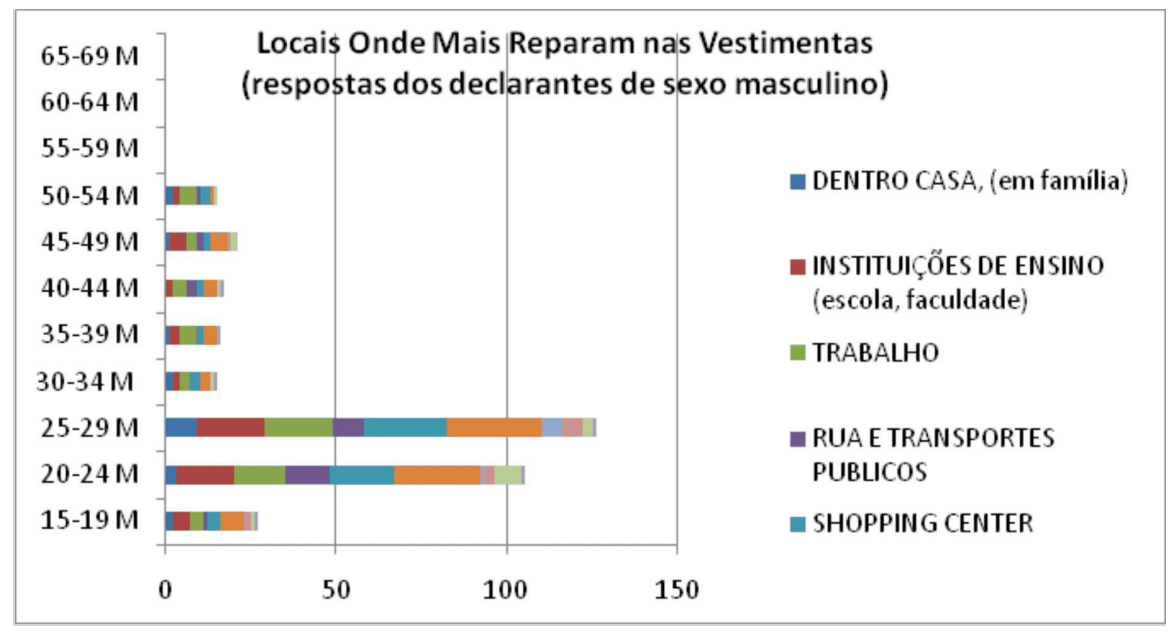

Fonte: Maia, pesquisa on-line https://www.facebook.com/carlosedumaia, 2015. 




Fonte: Maia, pesquisa on-line https://www.facebook.com/carlosedumaia, 2015.

Conclusões

Ao retirarmos do baú a geografia das vestimentas, percebeu-se que interessantes análises das vestimentas como objeto foram feitas por geógrafos clássicos. Contemporaneamente, indicaram-se, em rápidas pinceladas, que pesquisas em geografia da indústria recolocaram as vestimentas também como objetos de estudo. O que sugerimos neste texto, diferentemente dos trabalhos clássicos e contemporâneos aqui referenciados, é que as vestimentas são um tema para investigarmos as espacialidades e espaços-tempos, dado que elas mesmas, literalmente, se incorporam espaços-tempos, são constitutivas das espacialidades dos sujeitos e demonstram lugaridades (no caso exposto, da casa e da rua). Todavia, as possibilidades de estudos em "geografias das vestimentas" são inúmeras e gostaríamos de sugerir, por exemplo, as seguintes pistas: as territorialidades definidas em situações de dresscode; os acessos e as restrições aos territórios conferidos pela vestimenta; os espaços de vestimenta mínima e de uniformização na pós-modernidade e os não lugares ou deslugaridades; vestimentas, relações de gênero e espacialidades; os lugares de moda e a moda nos lugares; entre outras. Enfim, o ser humano se distingue dos demais animais até por se vestir e, com isso, muda de aparência, afirma posições políticas e status, comunica sem dizer palavras, diferencia ou assemelha-se aos 
outros, aproxima-se ou distancia-se, agrega-se ou separa-se. Não se pode negar que em aí existam geografias. Enfim, parafraseando Denis Cosgrove diríamos que “a geografia está em toda vestimenta”!

\section{Notas}

1. Bolsista financiado pela CAPES processo n. 2305-14-3 no laboratório ENEC/ Sorbonne/Paris IV, no período de agosto de 2014 a janeiro de 2015.

2. "A vestimenta (do latim vestir, cobrir, cercar) designa 'qualquer objeto improvisado ou fabricado para cobrir o corpo humano, tendo diversos fins: proteção, dissimulação, sinal de reconhecimento.' Veste-se” (Tradução nossa).

3. "Se não for seguido por um determinante (vestimenta de noite, vestimenta esportiva etc.) uma peça determinada de roupa, geralmente uma pequena coisa extra, casaco ou agasalho, que uma mulher, por exemplo, usará numa saída noturna, prevenindo o frescor da noite" (Tradução nossa).

4. "Em que se expressa hábitos, disposições e preferências de cada grupo" (Tradução nossa).

5. "O material que o Quirguistão criou para o uso em sua vida de viagens periódicas, a forma da sua tenda, de suas vestimentas, carregam um conjunto em que tudo permanece como a personificação de um gênero de vida" (Tradução nossa).

6. "Para o conhecimento do indivíduo, a vestimenta oferece um documento de primeira classe e o ditado 'O hábito não faz o monge' é de uma precisão totalmente aproximativa. Mas o que é verdadeiro para um indivíduo é muito mais para uma comunidade: a vestimenta torna-se uma espécie de uniforme, cujas modificações sucessivas coincidem quase sempre com movimentos gerais da sociedade e cujos caracteres dominantes externalizam certos aspectos do temperamento comum” (Tradução nossa).

7. "Detenhamo-nos primeiramente nisto que se poderia chamar de uma significação indireta. Por exemplo, a vestimenta, em muitos casos, constitui uma distinção de origem étnica ou nacional [...]. Até então, a vestimenta evoca indiretamente as influências que a natureza e as ocupações correntes podem exercer sobre as suas mentalidades" (Tradução nossa).

8. "O que fica claro também na aparência geral do vestuário é a alegria de viver ou a sombria resignação ao destino. Aqui, ricos ou pobres, citadinos ou camponeses todos têm prazer em se vestir, buscando aprovação e brilho, competindo com seu narcisismo [...]. Em suma, a vestimenta nos informa sobre as influências, mas ao mesmo tempo nos permite medir o grau de plasticidade de um grupo, o seu apego às tradições locais, aos costumes religiosos, a tudo o que constitui a espinha dorsal da alma coletiva [...] se após esta amostragem de fatos significativos tivermos ainda que provar o valor psicológico da vestimenta, seria suficiente, sem dúvida, lembrar-se que sempre existiu uma "moral da vestimenta”. [...] Muito melhor, há uma "política da vestimenta”, a qual seria muito interessante de estudar no tempo e no espaço. Não são só as leis suntuá- 
rias [...] são, sobretudo, decisões que, através do uso das vestimentas, tendem a se inclinar em certo sentido os hábitos morais dos povos " (Tradução nossa).

9. "Se não a invenção ao menos a descoberta de uma nova ciência a qual ele (Hardy) deu no nome de Geografia psicológica” (Tradução nossa).

10. "Para se defender, era necessário ter vestimentas suficientemente quentes e numerosas. O vestuário constituía um capital de alto valor” (Tradução nossa).

11. "As vestimentas foram muito tempo caras e constituíam a prova de riqueza, no início, elas chegavam da França, mas em quantidade insuficiente [...]. Houve um importante mercado clandestino de tecido [...]” (Tradução nossa).

12. "Sobretudo curto, forrado de pele de carneiro, grande gola de pele - e mulheres - de grossos saiotes de lã superpostos” (Tradução nossa).

13. "Não se casaria com a criatura (mulher) que não soubesse tecer o pano" (Tradução nossa).

14. "Era um elemento capital da luta contra o inverno a ponto que, por vezes, casava-se para ter vestimentas quentes; um provérbio diz: 'Um homem sem mulher não toma inverno”" (Tradução nossa).

15. "Durante séculos a moda permaneceu como fenômeno urbano. Não é necessário esquecer que as cidades não eram isso que elas são hoje: uma pequena parte da população vivia lá” (Tradução nossa).

16. "[...] utilizarei o termo ajuntamento para me referir a qualquer conjunto de dois ou mais indivíduos cujos membros incluem todos e apenas aqueles que estão na presença imediata uns dos outros num dado momento" (Goffman, 2010, p. 28).

\section{Referências}

ALBERONI, F. Observações sociológicas sobre o vestuário masculino. In: ECO, H.; SIGURTA, R.; LIVOLSI, M. et al. Psicologia do vestir. 2. ed. Lisboa: Assírio e Alvim, 1982. p. 51-63.

ALCÂNTARA, M. A missão da roupa: da moda ao discurso nas performances. São Paulo: 2010.

BOLLNOW, O. F. O homem e o espaço. Curitiba: Ed. UFPR, 2008.

DAMATTA, R. O que faz o Brasil, Brasil? Rio de Janeiro: Rocco, 1984.

. A casa \& a rua. 5. ed. Rio de Janeiro: Rocco, 1997.

DEFFONTAINES, P. L' homme et l'hiver au Canada.10 ème édition. Paris: Gallimard, 1957.

DEMANGEON, A. La géographie psychologique. Annales de Géographie,t. 49, n. 278-279, p. 134-137, 1940. Disponível em: <http://www.persee.fr/web/revues/ home/prescript/article/geo_0003-4010_1940_num_49_278_11574 >. Acesso em: 2 jun. 2014.

ECO, H. O hábito fala pelo monge. In: ECO, H.; SIGURTA, R.; LIVOLSI, M. et al. Psicologia do vestir. 2. ed. Lisboa: Assírio e Alvim, 1982. p. 7-20. 
ERAYDIN, A.; ERENDIL, A. The role of female labour in industrial restructuring: new production processes and labour market relations in the Istanbul clothing industry. Gender, Place and Culture: Journal of Feminist Geography, v. 6, n. 3, p. 259-272(14), 1 September, 1999.

FARIA, E. Dicionário Escolar Latino-Português. 3. ed. Rio de Janeiro: MEC, 1962. GODART, F. Sociología de la moda. Buenos Aires: Edhasa, 2012.

GOFFMAN, E. Comportamento em lugares públicos. Petrópolis, RJ: Vozes, 2010.

GUILLEMARD, C. Les mots du costume. Paris: Belin, 1991.

GRANDE DICIONÁRIO HOUAISS DA LÍNGUA PORTUGUESA. 2012. Disponível em: <http://houaiss.uol.com.br/busca?palavra=vestimenta $>$. Acesso em : 2 abr. 2015.

HANSEN, H. H. Histoire du costume. Paris: Flammarion, 1956.

HARDY, G. La géographie psychologique. 2 ème édition. Paris: Gallimard, 1939.

JAMES, L. A roupa e a moda: uma história concisa. São Paulo: Companhia das Letras, 1989.

MAIA, R. Sobre portas, paredes e afetos: casa, territorialidade e identidade entre os segmentos populares.Terr@Plural (UEPG. Online), v. 6, p. 339-352, 2012. Disponível em: <http://www.revistas2.uepg.br/index.php/tp/article/ viewFile/3440/2997>. Acesso em: 7 abr. 2015.

. Casa que te quero casa: reflexões sobre as formas e funções das moradias populares. In: XV Encontro da Anpur, 2013, Recife. Anais do XV Anpur, Recife, 2013. p. 1-15. Disponível em: <http://unuhospedagem.com.br/revista/rbeur/index. php/anais/article/viewFile/4503/4372>. Acesso em: 7 abr. 2015.

MONTEIRO, G. Metalinguagem das roupas. Estética. São Paulo: USP/CEDE, 2009. Disponível em: <http://200.144.182.150/estetica/index.php/anteriores/79revista-2>. Acesso em: 31 out. 2014.

NERY, M. L. A evolução da indumentária: subsídios para criação de figurino. 3. reimpr. Rio de Janeiro: Senac Nacional, 2009.

ÖRMEN, C. Brève histoire de la mode. Paris: Hazan, 2011.

RATZEL, F. Essência, origem e difusão da civilização. In: MORAES, A. C. R. Ratzel. São Paulo: Ática, 1990. p. 129-140.

RÉCLUS, E. A complexidade da produção do espaço geográfico. In: ANDRADE, M. C. de (Org.). Elisée Reclus. São Paulo: Ática, 1985. p. 56-60.

RIELLO, G. História da moda: da Idade Média aos nossos dias. Lisboa: Texto \& Grafia, 2013.

SANTOS, M. Economia espacial: crítica e alternativas. São Paulo: Hucitec, 1979.

SENNET, R. O declínio do homem público: as tiranias da intimidade. 5. reimpr. São Paulo: Companhia das Letras, 1998.

SCOTT, A. J. The changing global geography of low-technology, labor-intensive industry: clothing, footwear, and furniture. World Development, v. 34, n. 9, p. 1517-1536, 2006. 
SIGURTA, R. Delineamentos psicológicos da moda masculina. In: ECO, H.; SIGURTA, R.; LIVOLSI, M. et al. Psicologia do vestir. 2. ed. Lisboa: Assírio e Alvim, 1982. p. 21-36.

SIMMEL, G. Philosophie de la mode. Paris: Éditions Allia, 2013.

SMITH, A.; PICKLES, J.; BEGG, R. et al. Outward processing, EU enlargement and regional relocation in the European textiles and clothing industry: reflections on the European Commission's communication on 'the future of the textiles and clothing sector in the enlarged European Union'. European Urban and Regional Studies, v. 12, n. 1, p. 83-91, 2005.

SORRE, M. Les fondements de la géographie humaine: les fondements biologiques. Paris: Armand Colin, 1947.

- Les fondements biologiques de la geographie humaine. Ecologie $\mathcal{E}$ Politique, n. 26, p. 189-199, 2002-2003. Disponível em: < http://www.cairn.info/ revue-ecologie-et-politique-2002-3-page-189.htm>. Acesso em: 31 out. 2014.

STEELE, V. Avant-propos. In: FOGG, M. Tout sur la mode: panorama des chefsd'œuvre et destechniques. Paris: Flammarion, 2013. p. 6-7.

TOKATLI, N.; KIZILGÜN, Ö. Upgrading in the global clothing industry: Mavi Jeans and the transformation of a Turkish firm from full $\square$ package to brand $\square$ name manufacturing and retailing. Economic Geography, v. 80, n. 3, p. 221-240, 2004.

TOKATLI, N. Single-firm case studies in economic geography: some methodological reflections on the case of Zara. Journal of Economic Geography, p. lbu 013, 2014.

TOUSSAINT-SAMAT, M. Histoire technique \& morale du vêtement. Paris: Bordas, 1990.

VIDAL DE LA BLACHE, P. Les conditions géographiques des faits sociaux. Annales de Géographie. 1902, t. 11, n. 55, p. 13-23. Disponível em: <http://www.persee. fr/web/revues/home/prescript/article/geo_0003-4010_1902_num_11_55_18145>. Acesso em: 31 out. 2014.

. Principes de géographie humaine. Paris: Armand Colin, 1941.

Bolsista financiado pela CAPES processo n. 2305-14-3 no laboratório ENEC/ Sorbonne/Paris IV, no período de agosto de 2014 a janeiro de 2015.

Carlos Eduardo Santos Maia - Possui Graduação em Geografia pela Universidade do Estado do Rio de Janeiro. Mestrado e Doutorado em Geografia pela Universidade Federal do Rio de Janeiro. Atualmente é professor associado pela Universidade Federal de Juiz de Fora.

Este artigo foi revisado por Janaynne Carvalho do Amaral, revisora textual da Divisão de Periódicos do CEGRAF - Centro Editorial e Gráfico UFG. 